\title{
Social Protection: To Target or Not to Target
}

\section{John Hoddinott}

\section{Two vignettes}

With the passage of the Old Age Security Act in 1952, Canada replaced a system of means-tested benefits with a universal Old Age Security (OAS) pension. Under this programme, described as the 'cornerstone of Canada's retirement income system' (Government of Canada, 2006), every citizen over the age of 65 receives Can $\$ 450$ per month. ${ }^{1}$ However, while Canada is a rich country, even its government faces competing demands on its resources. As a result, income received from the OAS is taxed at a special rate and above a certain income level, the taxation rate on OAS becomes 100 per cent. Since it makes no sense to pay out a transfer and then tax it back, individuals above the certain income level do not actually receive the OAS but they do report receiving the OAS on their tax return. They also report having paid tax equivalent to the OAS amount that was 'received'. To a casual observer, this pension is a means-tested income transfer. The Canadian government, however, maintains that the OAS is a universal transfer.

In the mid-1990s, the Government of Mexico had a number of programmes designed to reduce hunger and poverty among its citizens. These programmes, some of which had been operating for decades, included 15 different food subsidy programmes. Four of these were universal subsidies, including bread and tortillas in urban areas and maize and maize flour in rural areas, and these accounted for about twothirds of the food subsidy budget (Levy 2006). Most of the benefits of these universal programmes accrued to non-poor households. Levy and Rodriguez (2004) estimate that for every peso spent on the urban tortilla subsidy, less than 15 per cent actually reached poor households. The targeting of the bread programme was even worse. For a number of reasons, described in Levy (2006), in 1997, these food subsidies were replaced by a targeted conditional cash transfer programme called PROGRESA. ${ }^{2}$ Conservative assessments of the targeting of PROGRESA indicate that 62.4 per cent of beneficiary households are in the bottom two consumption deciles (see Morris et al. 2001 and Coady 2001).

\section{The case for targeting}

These vignettes, drawn from very different programmes being implemented in very different countries contain the three themes of this article: that targeting social protection programmes is a means to an end - where the end is ensuring that poor households are the ones who benefit from social protection programmes; that on balance, existing evidence suggests that targeted programmes, as currently practised around the developing world, do indeed deliver a greater share of programme benefits to poor households; and that targeted programmes are a mechanism by which the allocation mechanisms underlying such programmes can be made more transparent.

To understand the rationale behind targeting, suppose that our objective is to eliminate consumption poverty. Using household survey data, we graph consumption levels of individual households before any transfers to them (i.e. 'original income'), ordering them from worst to best off. This ordering is represented on the $x$-axis of Figure 1 , while a household's income after the transfer is given on the $y$-axis, i.e. 'final income'. The maximum and minimum household incomes in the survey are $Y_{\max }$ and $Y_{\text {min }}$, respectively, and $z$ is the poverty line. ${ }^{3}$ The optimal transfer scheme is one that gives a transfer to all poor households only (i.e. those with income less than z), with transfer levels equal to their individual 'poverty gaps', i.e. the distance between their original income and the poverty line, za. This transfer programme brings all poor households up to 


\section{Figure 1 Comparing universal and targeted transfers}

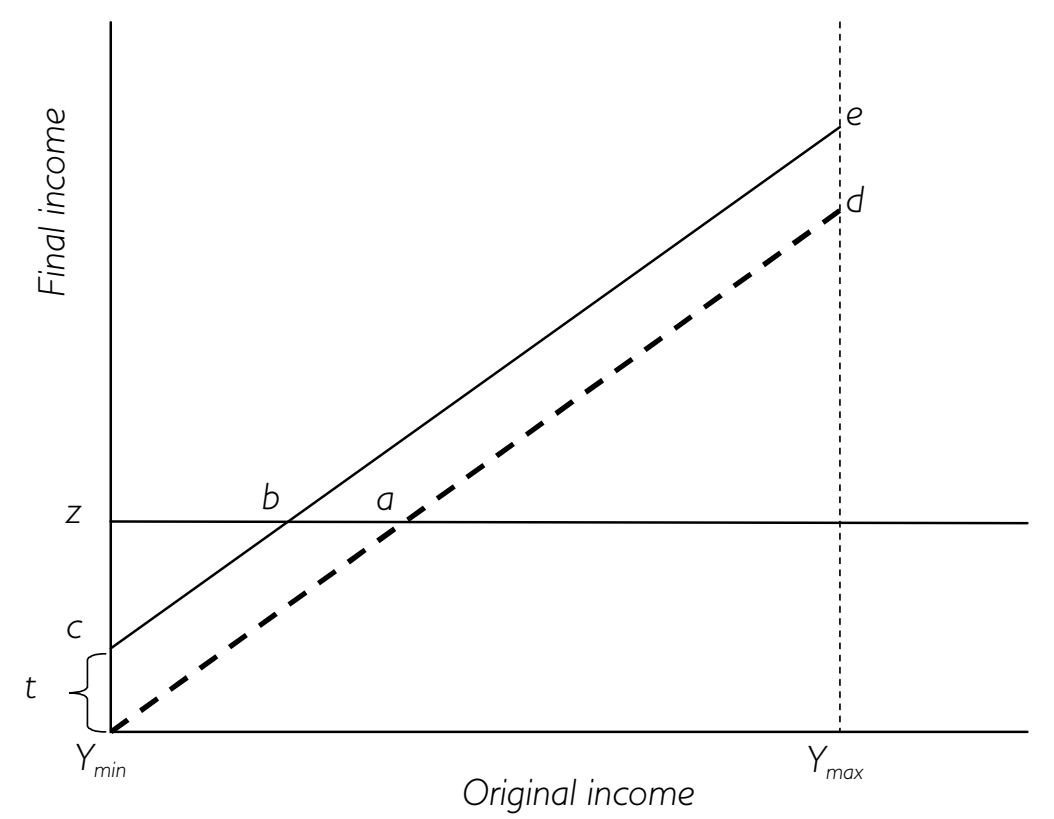

the poverty line; all non-poor households have equal final and original incomes. The poverty budget is thus represented by the area $z a Y_{\min }$ and this is the minimum budget required to eliminate poverty.

By contrast, consider the case of a universal programme, which gives the same transfer equal to $t\left(=c-Y_{\text {min }}\right)$ to all households irrespective of poverty status. Because of the 'leakage' of transfers to nonpoor households, the transfers to poor households are no longer sufficient to eliminate their poverty. There are two forms of 'inefficiency' associated with the uniform transfer: (1) non-poor households receive a transfer, and (2) some poor households (those in the line interval ba) receive transfers greater than their poverty gaps. These inefficiencies mean that the poverty impact of the uniform transfer scheme is less than that of the optimal transfer scheme, less by the area zcb. Not only does the universal scheme leak resources to non-poor beneficiaries, it fails to eliminate poverty.

This argument may sound all very well in theory, but does it work in practice? Coady et al. (2004a,b) constructed a database of 122 targeted anti-poverty interventions in 48 low- or middle-income countries. A common feature of these programmes is that they involved a transfer of resources to a beneficiary. As such, they included cash transfers (including welfare and social assistance payments, child benefits and non-contributory pensions), near-cash transfers (such as quantity-rationed subsidised food rations and food stamps), food transfers, universal food subsidies, nonfood subsidies, public works and social funds.

In order to compare the targeting of these different programmes, Coady et al. (2002b) developed a simple comparative measure: the share of programme resources transferred to a certain segment of the population divided by that group's share of the total population. ${ }^{4} \mathrm{~A}$ universal programme would have a ratio of one. To see why, consider the poorest 40 per cent of the population as ranked by income. Under a universal scheme where everyone gets the same - this group receives 40 per cent of programme benefits. If this was replaced by some form of targeting which produced a ratio $>1$, then the targeted programme would be increasing the share of resources to the poor relative to the universal programme.

Coady et al. (2002b) constructed this index for 85 programmes. They found that the median programme had a ratio of 1.25 , meaning that it 
transferred 25 per cent more resources to poor households (defined as households in the bottom two income or consumption quintiles) than would a (hypothetical) universal transfer. Median ratios were highest (1.50) for programmes that used some form of individual assessment such as means testing, lower (1.32) for programmes that used some form of categorical targeting such as targeting based on age and lowest of all (1.10) for programmes that relied on self-targeting such as self-targeted food subsidies. They found that countries with better capacity for programme implementation do better at directing benefits towards poorer members of the population, as do countries where governments are more likely to be held accountable for their behaviour.

While these examples point to the narrow economic case for targeting, they do not capture the third theme implicit within the vignettes. Calling a social protection programme 'universal' does not make it so nor does it ensure that the programme will necessarily benefit the poor. In Canada, it is politically unacceptable to describe the Old Age Security pension as means-tested even though a means test is clearly applied. In Mexico, universal subsidies clearly provided little benefit to the poorest segments of the population and some, such as the bread subsidy, provided virtually no benefits.

Lest these examples seem too idiosyncratic, consider the experiences surrounding the provision of old age pensions in South Africa and Namibia in the mid1990s. In South Africa, the physical delivery of pensions was undertaken by a government agency. Mobile automatic teller machines were driven through the countryside, stopping at meeting points such as markets or shops. As a result, take-up rates for this universal programme in rural areas were about 80 per cent (Case and Deaton 1998). By contrast, as a money-saving measure, in Namibia, the delivery of pensions was contracted out to a private firm. However, such contracts are by their very nature incomplete and as Hart et al. (1997) note, in such circumstances private providers have strong incentives to skimp on the quality of service provision. In the Namibian case, this took the form of minimising the number of locations at which the elderly could receive their money. In more remote northern areas, some pensioners had to travel as far as $100 \mathrm{~km}$ to receive their pensions. This feature, combined with difficulties in obtaining documentation and registering beneficiaries, resulted in, on average, 48 per cent of eligible individuals receiving this 'universal' transfer, with this figure falling as low as 30 or 34 per cent in some areas (Subbarao 1998).

Because all governments face budget constraints, all governments face difficult choices in deciding how to allocate their resources among competing ends, the identity of the beneficiaries and the means by which these resources are to be transferred. $A$ decision to target social protection programmes forces debates regarding these trade-offs into the open. Targeting makes (or should make) explicit who are the intended beneficiaries of a social protection programme and the debates that lead up to the criteria adopted for targeting require all parties involved - governments, donors, civil society representatives and prospective beneficiaries - to make clear what their social protection goals are and why targeting this particular group will help achieve these goals. Explicit targeting also provides a benchmark for assessing programme performance an obvious question for both monitoring and evaluation is, 'Are intended beneficiaries such as the poor actually receiving benefits?'

\section{The limits of targeting}

The arguments described above make a case for considering targeting social protection programmes. They do not imply that all such programmes should be targeted.

Decisions to target social protection interventions should be based on assessments of both the benefits and the costs of targeting. These costs take several forms, some of which are less visible than others. There are costs to individuals and households associated with targeting. For example, cash-forwork programmes involve households incurring an opportunity cost in terms of forgone income opportunities. Travelling to offices and lining up to be interviewed (e.g. when benefits are means-tested) has both financial and opportunity costs and there may be further costs associated with obtaining certifications required for the programme such as identity cards or proof of residency. There are administrative costs - the costs associated with identifying beneficiaries such as those incurred when implementing means testing of households or conducting a survey on which to base a poverty map. Even where targeting is delegated to nongovernment actors, as in the case of community- 
based targeting, costs of identifying beneficiaries persist even if they are less tangible, such as the opportunity cost of the time spent by community members in constructing lists of prospective beneficiaries. Even less visible are the social tensions generated when some individuals, but not others, are selected for programme participation. These costs may mean that less of the programme budget is available to be distributed to beneficiaries.

However, while targeting costs may increase as the targeting becomes finer, a targeted programme that serves a smaller number of people may require fewer staff to administer so that overall administrative costs might be lower. Further, tighter targeting - by reducing the number of beneficiaries - may make it possible to increase transfers to those individuals selected into the programme.

While the evidence suggests that targeting generally increases the share of benefits going to poor people, there are exceptions. Coady et al. (2004a,b) note that in their sample, 14 per cent of the programmes considered were regressive - that is, the poorest 20 per cent of households received less than 20 per cent of programme benefits - a figure that rises to 25 per cent if self-targeted food subsidies are included. Further, targeting does not mean that all poor households will be included - there can be errors of exclusion related to the inability of the programme to correctly identify potential beneficiaries. Poor targeting reflects bad design resources are transferred to individuals who were not in fact poor - or bad implementation. Successful targeting requires that programme administrators know who the poor are and where, and how, they

\section{Notes}

1 Subject to certain residency restrictions.

2 In 2000, the programme was modified and renamed Oportunidades.

3 The line $d Y_{\min }$ shows that, by definition, before the transfer programme is in place households' final incomes are equal to their original incomes.

\section{References}

Case, A. and Deaton, A. (1998) 'Large Cash Transfers to the Elderly in South Africa', Economic Journal 108: 1330-61

Chen, S., Ravallion, M. and Wang, Y. (2006) Di Bao: A Guaranteed Minimum Income in China's Cities? Policy Research Working Paper 3805, Washington DC: World Bank can best be reached. It also requires the ability to identify these individuals, households or groups. Absent either of these and targeting will not be effective.

Finally, targeting is only appropriate when it can be done in a manner that respects the dignity of the individuals who are to be assisted. While it is sometimes suggested that stigma be used as a means of targeting, this is wrong wrong wrong. Targeting is only a means to an end - where the end is the improvement in the wellbeing of beneficiaries. Not only does stigmatising beneficiaries not contribute to this objective, it can carry long-term social and psychological costs that far outweigh the benefits on offer.

\section{Conclusion}

When faced with the dilemma of 'To be or not to be', Hamlet was famously indecisive, opting first 'to be' before, courtesy of Laertes, becoming 'not to be' at the end of the play. Governments in developing countries do not have the luxury of indecision when it comes to choosing whether to target social protection programmes. This essay argues that there is a strong case for considering targeting. Targeting has the potential to increase transfers to poor households, a potential that is borne out by experiences from all parts of the developing world. But there are costs - some more visible than others - as well as benefits to targeting, and these costs must also be considered when the decision to target or not to target a social protection programme is being made.

4 See Chen et al. (2006) for a critique of this approach and a suggested alternative.

Coady, D. (2001) An Evaluation of the Distributional Power of PROGRESA's Cash Transfers in Mexico, Food Consumption Nutrition Division Discussion Paper 117, Washington DC: International Food Policy Research Institute

Coady, D., Grosh, M. and Hoddinott, J. (2004a) The Targeting of Transfers in Developing Countries: Review of Experience and Lessons, Washington DC: 
World Bank and International Food Policy

Research Institute (IFPRI)

Coady, D., Grosh, M. and Hoddinott, J. (2004b)

'Targeting Outcomes Redux', World Bank Research Observer 19: 61-85

Government of Canada (2006) Overview of the Old age Security Program. www.hrsdc.gc.ca/en/isp/ oas/oasoverview.shtml (accessed 12 January 2007) Hart, O., Shleifer, A. and Vishny, R. (1997) 'The Proper Scope of Government', Quarterly Journal of Economics 112: 1127-61

Levy, S. (2006) Progress Against Poverty: Sustaining Mexico's Progresa-Oportunidades Program, Washington DC: Brookings Institution Press
Levy, S. and Rodriguez, E. (2004) Economic Crisis, Political Transition and Poverty Policy Reform: Mexico's Progresa-Oportunidades Program, Policy Dialogue Series, Washington DC: Inter-American Development Bank

Morris, S., et al. (2001) 'Social Nutrition Programs with Explicit Targeting Strategies', mimeo, Washington DC: International Food Policy Research Institute (IFPRI)

Subbarao, K. (1998) Namibia's Social Safety Net: Issues and Options for Reform, Policy Research Working Paper 1996, Washington DC: World Bank 